\title{
Endodontics
}

\section{Coronal and apical leakage analysis of two different root canal obturation systems}

\section{Patricia Gimenez Oddoni(a) Isabel Mello(b) \\ Jeffrey Martin Coil(c) \\ João Humberto Antoniazzi(d)}

(a) DDS, private practice, São Paulo, SP, Brazil.

(b) PhD, private practice, São Paulo, SP, Brazil.

(c) PhD, Assistant Professor, School of Dentistry, University of British Columbia, Vancouver BC, Canada.

(d) PhD, Chairman, Department of Endodontics, School of Dentistry, University of São Paulo, São Paulo, SP, Brazil.

\begin{abstract}
This study compared the coronal and apical leakage of $\mathrm{AH}$ Plus with gutta-percha to that of Epiphany with Resilon. Twenty-four single rooted teeth were instrumented and divided into 2 groups according to the solutions for smear layer removal and the obturation materials employed: Group A - 17\% EDTA-T and AH Plus with gutta-percha; Group B - primer and Epiphany with Resilon. The Group B specimens were light-cured in the coronal area for $20 \mathrm{~s}$. The external root surfaces were covered with a double layer of ethyl cyanoacrylate, except for the apical foramen and the cavity access. The teeth were immersed in $0.5 \%$ methylene blue for $48 \mathrm{~h}$. The specimens were rinsed, dried and axially split for dye penetration measurement with the ImageLab 2.3 software. The $t$-test showed no significant differences for coronal leakage between the groups, but there were significant differences for apical leakage between the groups $(P<0.05)$. AH Plus with gutta-percha and Epiphany with Resilon provided the same coronal seal, whereas Epiphany with Resilon provided the best apical seal.
\end{abstract}

Descriptors: Root canal obturation; Dental leakage.

Corresponding author:

Isabel Mello

Rua lliria, 203

São Paulo - SP - Brazil

CEP: 04284-060

E-mail:imello2@hotmail.com 


\section{Introduction}

The goals of modern endodontic therapy are cleaning, shaping, disinfection and three-dimensional obturation of the root canal system that does not allow leakage and promotes periapical healing. ${ }^{1,2}$ The sealing ability of the sealers used plays an important role in achieving this goal.

There are different sealers available such as zinc oxide-eugenol, calcium hydroxide, resin, glass ionomer or silicone. ${ }^{3}$ Resin-based root canal sealers associated to gutta-percha have been used for many years with clinical success. ${ }^{4}$ AH Plus is a well established resin-based sealer and has good sealing properties. ${ }^{5-11}$ Recently, Resilon, a new thermoplastic, filled polymer has been introduced and has the potential to challenge gutta-percha as a root filling material. ${ }^{12,13}$ This material is used with Epiphany, a dual-cured resin sealer and a self-etching primer and forms a single monoblock in the root canal system. ${ }^{14}$

Several studies have examined whether apical or coronal leakage may adversely affect the success of root canal therapy., ,7,13,15-18 Therefore, leakage studies on sealers remain important and necessary to determine the most suitable obturation materials for achieving therapeutic success. Limited data is available about the sealing properties of Epiphany/Resilon. Because of the ability to provide an immediate light-cured seal, Epiphany/Resilon, and purportedly a monoblock obturation, could offer some advantages over the traditional obturating materials. The aim of this study was to compare both coronal and apical leakages of a traditional obturating material to those of a new obturation system.

\section{Material and Methods Sample selection}

Twenty-four freshly extracted single-rooted maxillary and mandibular human teeth were radiographed to confirm the presence of one canal, mature apex, and absence of resorption or endodontic obturation. They were immersed in saline solution for $72 \mathrm{~h}$ to maintain hydration.

\section{Sample preparation}

After access preparation, a \#10 K-type file was used to determine the working length by penetrating the apical foramen and pulling back $1 \mathrm{~mm}$. The coronal thirds were prepared with \#2 and \#3 Gates Glidden drills, and the middle and apical thirds were prepared with K-files (Dentsply-Tulsa Dental, Tulsa, OK, USA) up to file \#45. During instrumentation, $1 \%$ sodium hypochlorite and Endo-PTC (urea peroxide + Tween 80 + carbowax - Farmácia de Manipulação Fórmula e Ação, São Paulo, SP, Brazil) were used as chemical adjuncts. After instrumentation, the canals were rinsed with $5 \mathrm{ml}$ of $1 \%$ sodium hypochlorite followed by a final rinse with $5 \mathrm{ml}$ of distilled water.

\section{Experimental procedures}

The teeth were randomly divided into 2 experimental groups according to Table 1. For the methodology control, two teeth were completely covered with cyanoacrylate and two teeth had their foramen and access cavity sealed.

For smear layer removal in Group A, a final rinse with $10 \mathrm{ml}$ of 17\% EDTA-T (Farmácia de Manipulação Fórmula e Ação, São Paulo, SP, Brazil) for 3 min was performed; for Group B, the primer (Pentron Clinical Technologies, LLC Wallingford, CT, USA) was applied with a specific microbrush for 3 min and the canals were dried with paper points. The Epiphany (Pentron Clinical Technologies, LLC Wallingford, CT, USA) and AH Plus (Dentsply-Tulsa Dental, Tulsa, OK, USA) sealers were manipulated according to the manufacturers' instructions. The sealers were placed into the canals using the master point: for group A, gutta-percha (DentsplyTulsa Dental, Tulsa, OK, USA) was used and for group B, Resilon (Pentron Clinical Technologies, LLC Wallingford, CT, USA). The lateral condensation technique was used. The specimens of Group B were light-cured on the coronal area for $20 \mathrm{~s}$. No

Table 1 - Experimental groups, solutions for smear layer removal and obturation materials used.

\begin{tabular}{c|c|c|c}
\hline $\begin{array}{c}\text { Group } \\
(\mathrm{n}=10)\end{array}$ & $\begin{array}{c}\text { Solution for smear } \\
\text { layer removal }\end{array}$ & Sealer & Point \\
\hline A & $17 \%$ EDTA-T & AH Plus & gutta-percha \\
\hline B & Primer & Epiphany & Resilon \\
\hline
\end{tabular}


temporary or permanent filling was placed over the root canal obturations.

\section{Microleakage test}

The external root surfaces were covered with a double layer of ethyl cyanoacrylate, except for the apical foramen and the access cavity. The teeth were immersed in $0.5 \%$ methylene blue for $48 \mathrm{~h}$. Afterwards, they were washed in running water for 1 $\mathrm{h}$ and dried. The crowns were sectioned from the roots and the roots were split axially into two halves for dye penetration measurement.

\section{Material analysis}

The two halves of each specimen were scanned and saved at 300 dpi each. The digital images were analysed by the ImageLab 2.3 software, using a tool that measures the distance between two points. The dye microleakage was evaluated by selecting the deepest longitudinal dye penetration towards both coronal and apical directions. The data was recorded in a chart and statistically analyzed at the 5\% level of significance.

\section{Results}

The means and standard deviations of the groups tested are shown in Table 2. The $t$-test showed no differences for coronal leakage between the groups, but there were differences for apical leakage between the groups, where Group B exhibited a better sealing $(P<0.05)$.

\section{Discussion}

In the present study, both groups had the same coronal leakage. In spite of the light curing procedure of the coronal area recommended by the

Table 2 - Means (in pixels) and standard deviations of dye leakage.

\begin{tabular}{c|c|c}
\hline Group & \multicolumn{2}{|c}{ Mean and Standard Deviation } \\
\hline & Coronal Leakage & Apical Leakage \\
\hline A & $27.3000 \pm 25.5476^{a}$ & $84.6000 \pm 37.7071^{\mathrm{b}}$ \\
\hline B & $46.6000 \pm 28.5354^{\mathrm{a}}$ & $53.3000 \pm 23.1087^{\mathrm{c}}$ \\
\hline
\end{tabular}

Equal letters in the respective column indicate statistically homogeneous groups $(P<0.05)$.
Epiphany manufacturer being right after obturation, Epiphany with Resilon did not provide a better coronal seal than AH Plus with gutta-percha. The manufacturer's instruction to immediately lightcure the coronal root filling to create a coronal seal may limit the flow of the resin sealer for stress relief. ${ }^{19}$ Furthermore, manipulation of the partially polymerized sealer during condensation may disrupt developing bonds between self-etching primer and root dentin. ${ }^{20}$ Group B exhibited a better apical sealing than Group A. Other authors, using a silver tracer penetration protocol also found that the quality of the apical seal achieved with the Epiphany with Resilon root filling material was not superior to that of gutta-percha with AH Plus. ${ }^{21}$ However, studies employing bacteria showed that gutta-percha used with different sealers exhibited a lower sealing ability when compared to that of Epiphany with Resilon. ${ }^{12,13}$ Such discrepancies are probably due to differences in methodology and sample size. Analysis of the sealing ability of a new material under different conditions is therefore very important. Dye penetration is a methodology widely used for leakage studies and easy to reproduce. ${ }^{5,8,11}$ The control groups had expectable results and validated the methodology employed.

To achieve a successful endodontic treatment, the root canal filling material must seal the canal space both apically and coronally to prevent the ingress of microorganisms or tissue fluids into the canal space. Apical and coronal leakages are reported to be important reasons for root canal treatment failure..$^{4,73,15-18}$ The sealing quality of a root canal filling depends much on the sealing ability of the sealer. Excellent sealing has been achieved by resinbased sealers. ${ }^{5,-9,11,18}$ AH Plus, an epoxy-resin based sealer used with gutta-percha, was selected for this study based on the good sealing results found in the literature. ${ }^{5-11}$ This sealer also has good adhesion to dentin which could enhance its sealing ability. ${ }^{3,22}$

The release of new materials demands research about their different properties. Epiphany is a dualcured resin sealer which should be used with a selfetching primer. Resilon is a thermoplastic, filled polymer material that could replace gutta-percha. The combination of Resilon, Epiphany and the 
primer has been reported to create a monoblock obturation, where the Resilon is chemically bonded to the Epiphany and the Epiphany is bonded to dentin. ${ }^{12-14}$ Neither the gutta-percha or the AH Plus are capable of chemical bonding.

It is relevant to remember that after root canal preparation, the smear layer should be removed..$^{15,17,23}$ EDTA-T is a chelator + detergent used for smear layer removal and it was used in Group A. ${ }^{24}$ For Group $\mathrm{B}$, a specific self-etching primer was used according to the manufacturer's instructions. A review of a large number of published leakage studies points to general agreement that leakage occurs between the root filling and the root canal wall. ${ }^{1}$ Therefore, anything that may influence the adaptation of the root filling to the canal wall is of great significance in determining the degree and the extent of leakage, and ultimately the prognosis of the endodontic therapy.

\section{References}

1. Wu MK, De Gee AJ, Wesselink PR. Leakage of AH26 and Ketac-Endo used with injected warm gutta-percha. J Endod. 1997;23(5):331-6.

2. Yared GM, Bou Dagher F. Sealing ability of the vertical condensation with different root canal sealers. J Endod. 1996;22(1):6-8.

3. Saleh IM, Ruyter IE, Haapasalo M, Orstavik D. The effects of dentine pretreatment on the adhesion of root-canal sealers. Int Endod J. 2002;35(10):859-66.

4. Cohen S, Hargreaves KM. Pathways of the pulp. $9^{\text {th }}$ ed. St. Louis: Mosby Elsevier; 2006.

5. De Almeida WA, Leonardo MR, Tanomaru Filho M, Silva LAB. Evaluation of apical sealing of three endodontic sealers. Int Endod J. 2000;33(1):25-7.

6. Kayaoglu G, Erten H, Alaçam T, Orstavik D. Short-term antibacterial activity of root canal sealers towards Enterococcus faecalis. Int Endod J. 2005;38(7):483-8.

7. Kopper PM, Figueiredo JA, Della Bona A, Vanni JR, Bier CA, Bopp S. Comparative in vivo analysis of the sealing ability of three endodontic sealers in post-prepared root canals. Int Endod J. 2003;36(12):857-63.

8. Mello I, Robazza CR, Antoniazzi JH. Influence of Er:YAG laser irradiation on apical sealing of four different sealers. Braz Dent J. 2004;15(3):190-3.

9. Miletic I, Ribaric SP, Karlovic Z, Silvana J, Bosnjac A, Anic I. Apical leakage of five root canal sealers after one year of storage. J Endod. 2002;28(6):431-2.

10. Saleh IM, Ruyter IE, Haapasalo M, Orstavik D. Survival of Enterococcus faecalis in infected dentinal tubules after root
This study reports short-term leakage values, but the results may change with time. Further studies should be done regarding microleakage and other properties of Epiphany/Resilon.

\section{Conclusions}

Under the conditions of the present study, both obturation systems did not provide a perfect seal. AH Plus with gutta-percha and Epiphany with Resilon provided the same coronal sealing, whereas Epiphany with Resilon provided the best apical seal.

\section{Acknowledgements}

This research was supported by grants from The State of São Paulo Research Foundation (FAPESP), São Paulo, Brazil, as part of a scientific initiation program. canal filling with different root canal sealers in vitro. Int Endod J. 2004;37(3):193-8.

11. Sevimay S, Kalayci A. Evaluation of apical sealing ability and adaptation of two resin-based sealers. J Oral Rehabil. 2005;32(2):105-10.

12. Shipper G, Orstavik D, Teixeira FB, Trope M. An evaluation of microbial leakage in roots filled with a thermoplastic synthetic polymer-based root canal filling material (Resilon). J Endod. 2004;30(5):342-7.

13. Shipper G, Teixeira FB, Arnold RR, Trope M. Periapical inflammation after coronal microbial inoculation of dog roots filled with gutta-percha or Resilon. J Endod. 2005;31(2):91-6.

14. Versiani MA, Carvalho-Junior JR, Padilha MI, Lacey S, Pascon EA, Sousa-Neto MD. A comparative study of physicochemical properties of AH Plus and Epiphany root canal sealants. Int Endod J. 2006;39(6):464-71.

15. Cobankara FK, Adanr N, Belli S. Evaluation of the influence of smear layer on the apical and coronal sealing ability of two sealers. J Endod. 2004;30(6):406-9.

16. Cobankara FK, Adanir N, Belli S, Pashley DH. A quantitative evaluation of apical leakage of four root-canal sealers. Int Endod J. 2002;35(12):979-84.

17. Economides N, Kokorikos I, Kolokouris I, Panagiotis B, Gogos C. Comparative study of apical sealing ability of a new resin-based root canal sealer. J Endod. 2004;30(6):403-5.

18. Leonardo MR, Salgado AA, Da Silva LA, Tanomaru Filho M. Apical and periapical repair of dog's teeth with periapical lesions after endodontic treatment with different root canal sealers. Pesqui Odontol Bras. 2003;17(1):69-74. 
19. Davidson CL, De Gee AJ. Relaxation of polymerization contraction stresses by flow in dental composites. J Dent Res. 1984;63(2):146-8

20. Tay FR, Loushine RJ, Lambrechts P, Weller RN, Pashley DH. Geometric factors affecting dentin bonding in root canals: a theoretical modeling approach. J Endod. 2005;31(8):584-9.

21. Tay FR, Loushine RJ, Weller RN, Kimbrough WF, Pashley $\mathrm{DH}$, Mak YF et al. Ultrastructural evaluation of the apical seal in roots filled with a polycaprolactone-based root canal filling material. J Endod. 2005;31(7):514-9.
22. Pecora JD, Cussioli AL, Guerisoli DM, Marchesan MA, Sousa-Neto MD, Brugnera Jr A. Evaluation of Er:YAG laser and EDTA-C on dentin adhesion of 6 endodontic sealers. Braz Dent J. 2001;12(1):27-30.

23. Pommel L, About I, Pashley D, Camps J. Apical leakage of four endodontic sealers. J Endod. 2003;29(3):208-10.

24. Scelza MF, Antoniazzi JH, Scelza P. Efficacy of final irrigation - a scanning electron microscopic evaluation. J Endod. 2000;26(6):355-8. 